\title{
Preparation of High Purity Neodymium Oxide from Brazilian Monazite by Ion Exchange
}

\author{
Carlos Alberto da Silva Queiroz ${ }^{1}$, José Antonio Seneda ${ }^{1}$ and Walter dos Reis Pedreira Filho ${ }^{2}$ \\ 1. IPEN/CNEN-SP (Instituto de Pesquisas Energéticas e Nucleares/Comissão Nacional de Eneergia Nuclear-São Paulo), Cidade \\ Universitária, São Paulo 05508-000, Brazil \\ 2. Fundação Jorge Duprat Figueiredo de Segurança e Medicina do Trabalho-FUNDACENTRO, São Paulo 05409-002, Brazil
}

Received: March 02, 2015 / Accepted: May 06, 2015 / Published: July 31, 2015.

\begin{abstract}
A simple and economical chemical process for obtaining high purity neodymium oxide is discussed. The raw material in the form of RE (rare earth) carbonates is produced industrially in Brazil from monazite. Using this concentrate as the feed material, ion exchange with a strong cationic resin, commonly used for water treatment, and without the use of retention ions was used for the fractionating of the REE (rare earth elements). The eluent was ammonium salt of EDTA (ethylenediaminetetraacetic acid) at $\mathrm{pH} 4.0$. The complex of EDTA-neodymium was transformed into neodymium oxides via oxalate precipitation. We produced $99.9 \%$ pure $\mathrm{Nd}_{2} \mathrm{O}_{3}$ in yields greater than or equal to $80 \%$. Molecular absorption spectrophotometry was used to monitor the neodymium content during the process and sector field inductively coupled plasma mass spectrometry was used to certify the purity of the neodymium oxides. The typical neodymium oxides obtained contained the followings contaminants in micrograms per gram: Sc (4.09); Y (0.39); La (0.78); Ce (5.62); Pr (4.56); Sm (11.10); Eu (1.10); Gd (14.30); Tb (29.3); Dy (4.15); Ho (8.39); $\operatorname{Er}$ (13.80); Tm (0.23); Yb (2.29); $\mathrm{Lu}$ (0.39). High purity neodymium oxides obtained from this procedure replaced the imported product used in research and development work on rare earth at IPEN/CNEN-SP (Instituto de Pesquisas Energéticas e Nucleares/Comissão Nacional de Eneergia Nuclear-São Paulo).
\end{abstract}

Key words: Neodymium oxide, elemental rare earths separation, rare earths.

\section{Introduction}

Neodymium is gaining more and more importance nowadays as an efficient component of permanent magnets which are used in generator motors, automobiles, hard disc drives and many other electronics devices. Another important application for neodymium is the production of lasers for use in dentistry and medicine. Also, neodymium is applied in advanced ceramics and special alloys. Currently, there are studies of new neodymium molecules for use in anticancer drugs $[1,2]$.

Brazil has a long tradition in industrial rare earth technology, from monazite ores mining to separation and production of rare earth concentrates. Using some

Corresponding author: Carlos Alberto da Silva Queiroz, Ph.D., research field: rare earths. E-mail: cqueiroz@ipen.br. rare earth concentrates produced industrially in Brazil, a group of researchers at the IPEN/CNEN-SP (Instituto de Pesquisas Energéticas e Nucleares/Comissão Nacional de Energia Nuclear-São Paulo), São Paulo, have been working for several years with the individual separation of REE (rare earth elements) [3-9]. Some high grade pure oxides, such as lanthanum, cerium, neodymium, praseodymium, samarium, gadolinium and yttrium have been produced and used as spec pure standards $[10,11]$.

In this work, the separation, enrichment and purification of neodymium was performed using a commercial rare earth carbonate concentrate low in cerium named LCC (low cerium carbonate) as the feed. This concentrate was produced industrially from the alkaline chemical treatment from Brazilian monazite sand. The separation of REE was achieved 
by a cationic ion exchange resin and ammonium salt of EDTA (ethilenediaminetetraacetic acid) as the eluent. Neodymium oxide at $99.9 \%$ purity was obtained. Molecular absorption spectrophotometry and SF ICP-MS (sector field inductively coupled plasma mass spectrometry) techniques were used as analytic controls to ensure the quality of neodymium oxide $[12,13]$. This procedure simplifies the EDTA elution that requires the use the retaining ions such as $\mathrm{Cu}$ and $\mathrm{Zn}$ (exist as Cu-EDTA and Zn-EDTA complexes), reported widely in Refs. [14-16]. No retaining ions were used in this study.

\section{Experiment}

\subsection{Starting Raw Materials}

A representative sample of the LCC was used. Its chemical composition is shown in Table 1. Nitric acid, acetic acid, ammonium salt of EDTA and others reagents were of analytical grade. The solutions of RE (rare earth) nitrates were prepared by the dissolution of LCC in nitric acid. The solutions of RE nitrates at 10-15 $\mathrm{g} \mathrm{RE}_{2} \mathrm{O}_{3} / \mathrm{L}$ were filtered to separate small amounts of residues left.

\subsection{Loading the Resin and Elution of the REE to Obtain $\mathrm{Nd}_{2} \mathrm{O}_{3} \geq 90 \%$ Purity: Ion Exchange-Stage 1}

The strong cationic exchanger S-100, produced by Bayer Co. in 50-100 meshes was used in this investigation. This resin is commonly used for water purification and freely available in Brazil. The solutions of REE nitrates at 10-15 $\mathrm{g} \mathrm{RE}_{2} \mathrm{O}_{3} / \mathrm{L}$ were passed continuously through a column system filled with the resin and subsequently rinsed with deionized water. The REE loaded in the resin were eluted with ammoniacal EDTA (0.005-0.010 M) at $\mathrm{pH}$ 3.5-4.0. The eluate was collected in fractions, precipitated as oxalates and then converted to oxides, by calcining at $900{ }^{\circ} \mathrm{C}$ (1-4 h). The ion exchange system was built with three columns, $300 \mathrm{~cm}$ in height and $12 \mathrm{~cm}$ in diameter connected in series. The system was able to handle $10 \mathrm{~kg}$ of rare earth oxides, in total. This set up produced an eluate from which it was possible to
Table 1 Composition of LCC concentrate.

\begin{tabular}{llll}
\hline Constituent & $\%$ & Constituent & $\%$ \\
\hline $\mathrm{La}_{2} \mathrm{O}_{3}$ & $42-47$ & $\mathrm{Y}_{2} \mathrm{O}_{3}$ & $1-3$ \\
$\mathrm{CeO}_{2}$ & $3-7$ & $\mathrm{CaO}$ & $4-5$ \\
$\mathrm{Pr}_{6} \mathrm{O}_{11}$ & $5-6$ & $\mathrm{SiO}_{2}$ & 0.3 \\
$\mathrm{Nd}_{2} \mathrm{O}_{3}$ & $30-34$ & $\mathrm{U}_{3} \mathrm{O}_{8}$ & n.d. \\
$\mathrm{Sm}_{2} \mathrm{O}_{3}$ & $4-5$ & $\mathrm{ThO}_{2}$ & n.d. \\
$\mathrm{Gd}_{2} \mathrm{O}_{3}$ & $2-4$ & & \\
\hline
\end{tabular}

Analysis by X-ray fluorescence, n.d. denotes not detected.

obtain neodymium oxide greater than $90 \%-95 \%$ purity with a $80 \%$ yield.

\subsection{Neodymium Purification-Ion Exchange Stage 2}

The neodymium oxide obtained using the procedure described above was refined further by using the same strong cationic resin in an ion exchange system comprised of five columns, $100 \mathrm{~cm}$ in height and $5 \mathrm{~cm}$ in diameter, connected in series.

The feed neodymium nitrate solution for this stage was prepared by dissolving of $90 \%-95 \%$ pure neodymium oxide produced in the previous stage in hot nitric acid. The required dilution was made to obtain neodymium nitrates of $10-15 \mathrm{~g} \mathrm{Nd}_{2} \mathrm{O}_{3} / \mathrm{L}$. The resin was loaded with approximately $200 \mathrm{~g} \mathrm{RE}_{2} \mathrm{O}_{3}$ (the maximum loading capacity of the system was $500 \mathrm{~g}$ $\mathrm{RE}_{2} \mathrm{O}_{3}$ ). As in the previous stage, the loaded resin was eluted with ammoniacal EDTA $0.01 \mathrm{~mol} / \mathrm{L}$ at $\mathrm{pH}$ 3.5-4.0. A final neodymium oxide with purity greater than $99.9 \%$ was obtained. A block diagram of this process is presented in Fig. 1.

\subsection{Oxalate Precipitation}

The eluted fractions were acidulated with $\mathrm{HNO}_{3}$ 1/1 to $\mathrm{pH} 1$. Then was added oxalic acid solution $20 \mathrm{~g} / \mathrm{L}$ until complete precipitation of the rare earth oxalates and allowed to rest for $4 \mathrm{~h}$. The precipitate was separated by vacuum filtration. Then, oxalates were calcined in a muffle furnace to $900{ }^{\circ} \mathrm{C}$ for up to $4 \mathrm{~h}$ in porcelain crucibles.

\subsection{Characterization and Analytical Control of the Process}

Molecular absorption spectrophotometry and SF 


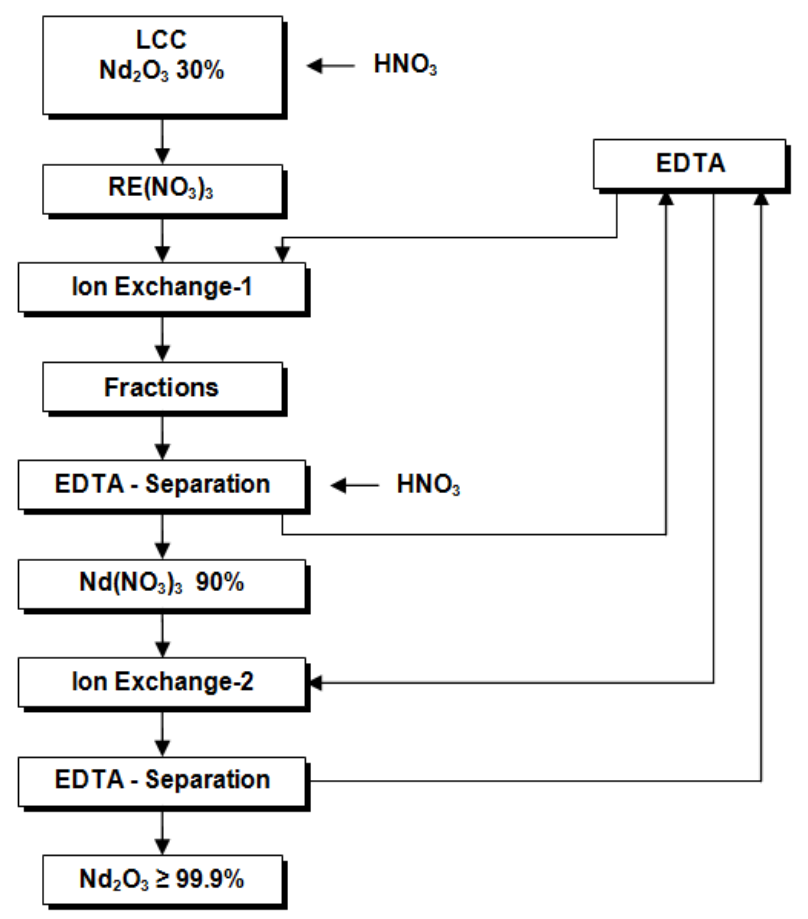

Fig. 1 Procedure for the preparation of pure neodymium oxides for use in research and development at IPEN/CNEN-SP (São Paulo).

ICP-MS, equipment supplied by Finnigan MAT (thermo mass spectometry), Bremen, Germany, were used to ensure the quality of the neodymium oxides. SF ICP-MS provided reliable and reproducible contaminant values in the range of $\mu \mathrm{g}^{-1}$.

\section{Results and Discussion}

The color of the neodymium oxide usually indicates its purity. Highly pure neodymium oxide has a clear blue color. When contaminated with traces of praseodymium, for instance, the neodymium oxide acquires a brown color. This visual inspection was a helpful indication of the purity of neodymium during the elution of REs from the resin.

Tables 2 and 3 display the elution data for Stages 1 and 2 , respectively. In the first stage of the process, neodymium oxide greater than $90 \%-95 \%$ purity was obtained with a yield of $80 \%$. The feed for the second stage, was the $90 \%-95 \%$ pure neodymium oxide produced in the first stage. This stage produced neodymium oxide greater than $99.9 \%$ purity.

The detailed analyses of neodymium oxide produced from current study are shown in Tables 4 and 5 .

Table 2 Data for elution and mass in the enrichment of neodymium, Stage 1.

\begin{tabular}{|c|c|c|c|c|c|}
\hline Fraction & Time (h) & Vol. (L) & $\mathrm{R}_{2} \mathrm{O}_{3}(\mathrm{~g})$ & Color & $\mathrm{Nd}_{2} \mathrm{O}_{3}(\%)$ \\
\hline 1 & 120 & 300 & 116.1 & Brown & \\
\hline 2 & 305 & 384 & 256.6 & Beige & \\
\hline 3 & 456 & 584 & 901.6 & Beige & \\
\hline 4 & 332 & 356 & 431.4 & Beige & \\
\hline 5 & 576 & 596 & 490.5 & Blue & 90 \\
\hline 6 & 666 & 469 & 236.6 & Blue & 90 \\
\hline 7 & 600 & 550 & 401.2 & Blue & 90 \\
\hline 8 & 96 & 130 & 78.5 & Blue & 90 \\
\hline 9 & 72 & 70 & 56 & Black & \\
\hline 10 & 72 & 28 & 23.5 & Black & \\
\hline 11 & 26 & 23 & 18 & Black & \\
\hline 12 & 98 & 80 & 73.3 & Black & \\
\hline 13 & 48 & 80 & 51.5 & Black & \\
\hline 14 & 172 & 75 & 110 & Black & \\
\hline 15 & 72 & 60 & 38.6 & Black & \\
\hline 16 & 24 & 40 & 27 & Black & \\
\hline 17 & 72 & 65 & 115.5 & Black & \\
\hline 18 & 48 & 40 & 43 & Brown & \\
\hline 19 & 48 & 60 & 54 & Brown & \\
\hline 20 & 24 & 50 & 69 & Yellow & \\
\hline 21 & 72 & 50 & - & Beige & \\
\hline
\end{tabular}


Table 3 Elution data for Stage 2: $\mathrm{RE}_{2} \mathrm{O}_{3}(\mathrm{~g})=215 \mathrm{~g}\left(\mathrm{Nd}_{2} \mathrm{O}_{3} \geq 90 \%\right)$, flow rate: $5 \pm 2 \mathrm{~mL} / \mathrm{min}$.

\begin{tabular}{|c|c|c|c|c|}
\hline Fraction & $\mathrm{RE}_{2} \mathrm{O}_{3}(\mathrm{~g})$ & $\mathrm{Sm}_{2} \mathrm{O}_{3}(\%)$ & $\mathrm{Pr}_{6} \mathrm{O}_{11}(\%)$ & $\mathrm{Nd}_{2} \mathrm{O}_{3}(\%)$ \\
\hline $1 \& 2$ & - & - & - & - \\
\hline 3 & 0.28 & - & - & - \\
\hline 4 & 0.42 & 64 & - & 26 \\
\hline 5 & 0.27 & 30 & - & 58 \\
\hline 6 & 0.22 & 19 & - & 77 \\
\hline 7 & 0.52 & 19 & - & 77 \\
\hline 8 & 0.60 & 12 & - & 85 \\
\hline 9 & 0.97 & 5 & - & 93 \\
\hline 10 & 0.52 & 1 & - & 95 \\
\hline 11 & 0.97 & - & - & 99 \\
\hline 12 & 4.30 & - & - & $>99$ \\
\hline 13 & 8.10 & - & - & $>99$ \\
\hline 14 & 14.4 & - & - & $>99$ \\
\hline 15 & 11.9 & - & - & $>99$ \\
\hline 16 & 9.70 & - & - & $>99$ \\
\hline 17 & 19.00 & - & - & $>99$ \\
\hline 18 & 18.60 & - & - & $>99$ \\
\hline 19 & 9.30 & - & - & $>99$ \\
\hline 20 & 43.10 & - & - & $>99$ \\
\hline 21 & 14.40 & - & - & $>99$ \\
\hline $21-B$ & 10.00 & - & - & $>99$ \\
\hline 22 & 15.68 & - & - & $>99$ \\
\hline 23 & 3.40 & - & - & $>99$ \\
\hline 24 & 3.30 & - & - & $>99$ \\
\hline 25 & 5.29 & - & 26.4 & 66 \\
\hline
\end{tabular}

Table 4 Comparison of REE impurities in neodymium oxide produced at IPEN/CNEN-SP vs. imported.

\begin{tabular}{lllll}
\hline Element & $\begin{array}{l}\mathrm{Nd}_{2} \mathrm{O}_{3} \geq 99.9 \% \\
\mathrm{IPEN} / \mathrm{CNEN}-\mathrm{SP} \\
(\mu \mathrm{g} / \mathrm{g})\end{array}$ & $\begin{array}{l}\mathrm{RSD}(\%) \\
(n=5)\end{array}$ & $\begin{array}{l}\mathrm{Nd}_{2} \mathrm{O}_{3} \geq 99.9 \% \\
\text { imported } \\
(\mu \mathrm{g} / \mathrm{g})\end{array}$ & $\begin{array}{l}\mathrm{RSD}(\%) \\
(n=5)\end{array}$ \\
\hline $\mathrm{Sc}$ & 4.09 & 3.32 & 1.01 & 2.51 \\
$\mathrm{Y}$ & 0.39 & 4.15 & 0.28 & 3.14 \\
$\mathrm{La}$ & 0.78 & 3.97 & 0.81 & 2.94 \\
$\mathrm{Ce}$ & 5.62 & 2.08 & 4.23 & 1.08 \\
$\mathrm{Pr}$ & 4.56 & 0.35 & 5.81 & 0.13 \\
$\mathrm{Sm}$ & 11.80 & 3.22 & 2.23 & 2.22 \\
$\mathrm{Eu}$ & 1.10 & 2.67 & 0.81 & 3.79 \\
$\mathrm{Gd}$ & 14.30 & 1.46 & 2.31 & 2.18 \\
$\mathrm{~Tb}$ & 20.30 & 3.97 & 15.40 & 1.95 \\
$\mathrm{Dy}$ & 4.15 & 2.17 & 6.25 & 2.78 \\
$\mathrm{Ho}$ & 0.39 & 0.74 & 7.46 & 1.37 \\
$\mathrm{Er}$ & 13.80 & 2.58 & 6.78 & 1.73 \\
$\mathrm{Tm}$ & 0.23 & 0.28 & 0.15 & 1.91 \\
$\mathrm{Yb}$ & 2.29 & 1.18 & 4.99 & 2.73 \\
$\mathrm{Lu}$ & 0.39 & 1.54 & 0.29 & 2.67 \\
\hline
\end{tabular}

RSD: relative standard deviation $(n=5)$. 
Table 5 Comparison of REE metallic impurities in neodymium oxide produced at IPEN/CNEN-SP vs. imported.

\begin{tabular}{|c|c|c|c|c|}
\hline Element & $\begin{array}{l}\mathrm{Nd}_{2} \mathrm{O}_{3} \geq 99.9 \% \\
\text { IPEN/CNEN-SP } \\
(\mu \mathrm{g} / \mathrm{g})\end{array}$ & $\begin{array}{l}\text { RSD }(\%) \\
(n=5)\end{array}$ & $\begin{array}{l}\mathrm{Nd}_{2} \mathrm{O}_{3} \geq 99.9 \% \\
\text { imported } \\
(\mu \mathrm{g} / \mathrm{g})\end{array}$ & $\begin{array}{l}\operatorname{RSD}(\%) \\
(n=5)\end{array}$ \\
\hline B & 0.46 & 3.85 & 0.31 & 2.51 \\
\hline $\mathrm{Ti}$ & 0.50 & 2.64 & 0.11 & 3.14 \\
\hline V & 0.66 & 1.71 & 0.21 & 3.95 \\
\hline $\mathrm{Cr}$ & 0.30 & 3.81 & 0.20 & 2.75 \\
\hline $\mathrm{Mn}$ & 0.84 & 4.81 & 0.38 & 2.55 \\
\hline $\mathrm{Fe}$ & 32.8 & 4.92 & 16.5 & 3.37 \\
\hline Co & 0.95 & 3.37 & 0.40 & 5.05 \\
\hline $\mathrm{Ni}$ & 7.27 & 2.44 & 5.31 & 2.12 \\
\hline $\mathrm{Cu}$ & 2.51 & 3,93 & 1.49 & 4.67 \\
\hline $\mathrm{Zn}$ & 3.87 & 2.75 & 1.72 & 3.91 \\
\hline $\mathrm{Sr}$ & 0.84 & 3.54 & 0.12 & 3.41 \\
\hline $\mathrm{Nb}$ & 0.99 & 3.67 & 0.15 & 3.75 \\
\hline Mo & 1.67 & 2.81 & 0.61 & 2.12 \\
\hline $\mathrm{Pd}$ & 2.61 & 4.28 & 0.56 & 3.27 \\
\hline $\mathrm{Sn}$ & 1.87 & 3.65 & 0.78 & 3.50 \\
\hline $\mathrm{Cd}$ & 2.95 & 4.37 & 0.90 & 4.12 \\
\hline $\mathrm{Sb}$ & 1.80 & 3.55 & 0.69 & 3.53 \\
\hline $\mathrm{Pb}$ & 3.02 & 2.28 & 2.51 & 3.85 \\
\hline $\mathrm{Bi}$ & 1.01 & 4.19 & 0.72 & 3.85 \\
\hline $\mathrm{Th}$ & 1.51 & 3.81 & 0.82 & 4.50 \\
\hline $\mathrm{U}$ & 2.05 & 3.38 & 0.94 & 3.24 \\
\hline
\end{tabular}

\section{Conclusions}

Using a cationic ion exchange resin S-100 with $0.01 \mathrm{~mol} / \mathrm{L}$ ammonium salt of EDTA at $\mathrm{pH} 4.0$ as the eluent, it was possible to obtain a highly pure neodymium oxide that can be used in the research and development at IPEN/CNEN-SP. The purification procedure tested in this work can be scaled up to a semi industrial level.

We have also $\mathrm{CeO}_{2} \geq 99.9 \%, \mathrm{La}_{2} \mathrm{O}_{3} \geq 99.9 \%$, $\operatorname{Pr}_{6} \mathrm{O}_{11} \geq 99.9 \%$ and $\mathrm{Sm}_{2} \mathrm{O}_{3} \geq 99.9 \%$ to obtained by this method, that is used for preparing rare earths oxides nanoparticles and applied in automotive catalyst to increasing its life time.

Further studies undertaken on the synthesis and chemical characterization of the neodymium acetates by Thermogravimetry, X-Ray Diffraction and Infrared Spectroscopy techniques are yet to be published.

\section{Acknowledgments}

We thank to IPEN/CNEN-SP and Fundação de Amparo e Pesquisa do estado de São Paulo-FAPESP for financial support.

\section{References}

[1] Feng, C., Gan, Q., Liu, X., and He, H. 2012. "Synthesis and Antitumor Activities of Rare Earth Substituted Phosphotungstates Containing 5-Fluorouracil." Journal of Rare Earths 30 (5): 467.

[2] Liu, X., Wang, S., and Feng, C. 2010. "Synthesis and Anticancer Properties of Tungstosilicic Polyoxometalate Containing 5-Fluorouracil and Neodymium." Journal of Rare Earths 28 (6): 965-8.

[3] Abrão, A. 1994. "Chemistry and Technology of the Rare Earths." Centro de Tecnologia Mineral/Conselho Nacional de Desenvolvimento Cientifico e Tecnológico. Accessed June 15, 2015. http://www.cetem.gov.br.

[4] Queiroz, C. A. S., and Abrão, A. 1982. "The Separation of Cerium and the Fractionation of Rare Earths from Mixed Chlorides." In Proceedings of the Annual 
Symposium of São Paulo State Academy of Sciences, 200-2.

[5] Queiroz, C. A. S., and Abrão, A. 1984. "Obtaining Pure Neodymium and Lanthanum Oxides from Mixed Rare Earths Chloride". In Proceedings of the Annual Symposium of São Paulo State Academy of Sciences, 57-73.

[6] Queiroz, C. A. S., and Abrão, A. 1990. "Some Aspects of the Analytical Control Applied to a Process of Rare Earths Fractionation". In Proceedings of the Annual Symposium of São Paulo State Academy of Sciences, 157-89.

[7] Vasconcellos, M. E., Queiroz, C. A. S., and Abrão, A. 2004. "Sequential Separation of the Yttrium-Heavy Rare Earths by Fractional Hydroxide Precipitation". $J$. Alloys of Compounds 374 (1-2): 405-7. Accessed June 15, 2015.

http://www.dx.doi.org/10.1016/jallcom.2003.11.038.

[8] Vasconcellos, M. E., Rocha, S. M. R., Pedreira, W. R., Queiroz, C. A. S., and Abrão, A. 2008. "Solubility Behavior of Rare Earths with Ammonium Carbonate and Ammonium Carbonate plus Ammonium Hydroxide: Precipitation of Their Peroxicarbonates." J. Alloys of Compounds 451 (1-2): 426-8. Accessed June 15, 2015. http://www.dx.doi.org/10.1016/j.jallcom.2007.04.163.

[9] Rocha, S. M. R., Queiroz, C. A. S., Lobo, R. M., Forbicini, C. A. L. G. O., Seneda, J. A., and Pedreira, W. R. 2008. "Lanthanum Influence on the Thermal Stability of Alumina." In Proceedings of the Brazilian Congress of Engineering and Materials Science, 544-9.

[10] Queiroz, C. A. S., and Abrão, A. 1986. "Obtaining Pure Gadolinium and Samarium from a Mixture of Rare Earth Carbonates by Ion Exchange." In Proceedings of the Annual Symposium of São Paulo State Academy of Sciences, 33-59.

[11] Queiroz, C. A. S., Matos, J. R., Vasconcellos, M. E., and
Abrão, A. 2002. "Thermoanalytical Characterization of Neodymium Peroxocarbonate." Journal Alloys of Compounds 344 (1-2): 32-5.

[12] Pedreira, W. R., Sarkis, J. E. S., Queiroz, C. A. S., Rodrigues, C., Tomiyoshi, I. A., and Abrão, A. 2003. "Determination of Trace Amounts of Rare-Earth Elements in Highly Pure Neodymium Oxide by Sector Field Inductively Coupled Plasma Mass Spectrometry (ICP-SFMS) and High-Performance Liquid Chromatography (HPLC) Techniquesm." Journal of Solid State Chemistry 171 (1): 3-6. Accessed June 15, 2015.

http://dx.doi.org.ez67.periodicos.capes.gov.br/10.1016/S0 022-4596(2)00003-8.

[13] Pedreira, W. R., Queiroz, C. A. S., Abrão, A., and Pimentel, M. M. 2004. "Quantification of Trace Amounts of Rare Earth Elements in High Purity Gadolinium Oxide by Sector Field Inductively Coupled Plasma Mass Spectrometry (ICP-MS)." J. Alloys of Compounds 374 (1-2): 129-32. Accessed June 15, 2015. http://www.dx.doi.org/10.1016/j.jallcom.2003.11.148.

[14] Spedding, F. H., Voigt, E. M., Gladrow, N. R., Sleight, J. E., Powell, J. E., Wright, J. M., Butler, T. A., and Figard, P. 1947. "The Separation of Rare Earths by Ion Exchange. II. Neodymium and Praseodymium." J. Am. Chem. Soc. 69 (11): 2786-92.

[15] Spedding, F. H., and Powell, J. E. 1954. "The Separation of Rare Earths by Ion Exchange. VII. Quantitative Date for the Elution of Neodymium." J. Am. Chem. Soc. 76 (9): 2545-50.

[16] Pavanini, L. A., Tfoni, E., and Serra, O. A. 1982. "Separating Rare Earths by Ion Exchange Method with $\mathrm{Zn}$ ions (II) and $\mathrm{Cu}$ (II) as Retainer Using Dowex 50-X-4 and Amberlite IR-120 Resins." In Proceedings of the Annual Symposium of São Paulo State Academy of Sciences, 225-44. 